\title{
Redox-induced structural changes in the di-iron and di-manganese forms of Bacillus anthracis ribonucleotide reductase subunit NrdF suggest a mechanism for gating of radical access
}

\author{
Kristīne Grāve ${ }^{1} \cdot$ Wietske Lambert $^{2} \cdot$ Gustav Berggren $^{3}$. Julia J. Griese ${ }^{1,4} \cdot$ Matthew D. Bennett $^{1} \cdot$ Derek T. Logan $^{5}$. \\ Martin Högbom ${ }^{1}$ (1)
}

Received: 8 July 2019 / Accepted: 6 August 2019 / Published online: 13 August 2019

(c) The Author(s) 2019

\begin{abstract}
Class $\mathrm{Ib}$ ribonucleotide reductases (RNR) utilize a di-nuclear manganese or iron cofactor for reduction of superoxide or molecular oxygen, respectively. This generates a stable tyrosyl radical (Y·) in the R2 subunit (NrdF), which is further used for ribonucleotide reduction in the R1 subunit of RNR. Here, we report high-resolution crystal structures of Bacillus anthracis $\mathrm{NrdF}$ in the metal-free form $(1.51 \AA)$ and in complex with manganese $\left(\mathrm{Mn}^{\mathrm{II}} / \mathrm{Mn}^{\mathrm{II}}, 1.30 \AA\right)$. We also report three structures of the protein in complex with iron, either prepared anaerobically ( $\mathrm{Fe}^{\mathrm{II}} / \mathrm{Fe}^{\mathrm{II}}$ form, $1.32 \AA$ ), or prepared aerobically in the photo-reduced $\mathrm{Fe}^{\mathrm{II}} / \mathrm{Fe}^{\mathrm{II}}$ form $(1.63 \AA)$ and with the partially oxidized metallo-cofactor $(1.46 \AA)$. The structures reveal significant conformational dynamics, likely to be associated with the generation, stabilization, and transfer of the radical to the R1 subunit. Based on observed redox-dependent structural changes, we propose that the passage for the superoxide, linking the FMN cofactor of NrdI and the metal site in NrdF, is closed upon metal oxidation, blocking access to the metal and radical sites. In addition, we describe the structural mechanics likely to be involved in this process.
\end{abstract}

Keywords Oxidoreductase $\cdot$ Metalloprotein $\cdot$ Carboxylate shift $\cdot$ X-ray crystallography $\cdot$ Ferritin superfamily

\section{Abbreviations}

ADO Aldehyde-deformylating oxygenase

BMM Bacterial multicomponent monooxygenase

Electronic supplementary material The online version of this article (https://doi.org/10.1007/s00775-019-01703-z) contains supplementary material, which is available to authorized users.

Derek T. Logan

derek.logan@biochemistry.lu.se

$\triangle$ Martin Högbom

hogbom@dbb.su.se

1 Department of Biochemistry and Biophysics, Stockholm University, Svante Arrhenius väg 16C, 10691 Stockholm, Sweden

2 PRA Health Sciences, Amerikaweg 18, 9407 TK Assen, The Netherlands

3 Department of Chemistry, Ångström Laboratory, Uppsala University, Lägerhyddsvägen 1, 75120 Uppsala, Sweden

4 Department of Cell and Molecular Biology, Uppsala University. BMC, Box 596, 75124 Uppsala, Sweden

5 Department of Biochemistry and Structural Biology, Lund University, Box 124, 22100 Lund, Sweden

\begin{tabular}{|c|c|}
\hline EPR & lectron paramagnetic resonance spectroscopy \\
\hline PDB & Protein data bank \\
\hline FMN & Flavin mononucleotide \\
\hline $\mathrm{R} 1$ & $\begin{array}{l}\text { Large subunit of ribonucleotide reductase, also } \\
\text { called } \alpha\end{array}$ \\
\hline R2 & $\begin{array}{l}\text { Radical-generating subunit of ribonucleotide } \\
\text { reductase, also called } \beta\end{array}$ \\
\hline R2lox & R2-like ligand-binding oxidase \\
\hline RNR & Ribonucleotide reductase \\
\hline TXRF & Total-reflection X-ray fluorescence \\
\hline
\end{tabular}

\section{Introduction}

Ribonucleotide reductase (RNR) is an essential enzyme in all domains of life. It catalyzes ribonucleotide reduction to the corresponding deoxyribonucleotides, which are further used in DNA synthesis and repair [1]. RNRs are complex enzymes that utilize radical chemistry for their catalytic activity. RNRs are grouped into classes I, II, and III (reviewed in [2,3]). Class I RNRs are oxygen-dependent and employ a radical-generating subunit denoted $\beta$ or $\mathrm{R} 2$. After generation, the radical is transferred in excess of 
$35 \AA$ to the active site in the catalytic subunit, denoted $\alpha$ or $\mathrm{R} 1$, generating a cysteine thiyl radical that initiates ribonucleotide reduction. With the exception of the recently discovered metal-free R2 subunit in common human pathogens [4, 5], R2 proteins house a di-metal cofactor responsible for generation and sometimes storage of the radical. The nature of the radical species and metal site differs between the R2 subunits; thus, class I RNRs are further subdivided into five subclasses (Ia-e): $\mathrm{Ia}\left(\mathrm{Fe}^{\mathrm{III} /}\right.$ $\mathrm{Fe}^{\mathrm{III}}$ - tyrosyl radical), $\mathrm{Ib}\left(\mathrm{Mn}^{\mathrm{III}} / \mathrm{Mn}^{\mathrm{III}}\right.$-tyrosyl radical), Ic $\left(\mathrm{Mn}^{\mathrm{IV}} / \mathrm{Fe}^{\mathrm{III}}\right)$, and $\left(\mathrm{Mn}^{\mathrm{IV}} / \mathrm{Mn}^{\mathrm{III}}\right)$ in the recently proposed class Id [2, 3, 6-8]. The metal-free R2, denoted class Ie, requires the flavoprotein $\mathrm{NrdI}$ and molecular oxygen for generation of a stable 3,4-dihydroxyphenylalanine (DOPA) radical [4].

Many organisms have been found to utilize more than one class of RNR, most likely depending on their ecological niche and lifecycle [9]. Similarly, Bacillus anthracis (Ba), a Grampositive zoonotic spore-forming bacterium and the causative agent of anthrax, encodes two types of RNRs belonging to classes III and Ib. In contrast to the obligate anaerobic class III enzyme, the class Ib RNR is active during aerobiosis [3], i.e., the active stages of anthrax, and thus may represent an attractive drug target. Interestingly, the di-manganese metallo-cofactor of class Ib R2 (NrdF) is unreactive towards molecular oxygen and requires an activase, the flavoprotein NrdI, to provide superoxide as the oxidant of the metal site [10]. The NrdF-NrdI complex forms a channel, presumed to facilitate superoxide delivery to the $\mathrm{Mn}_{2}^{\mathrm{II} / \mathrm{II}}$ metallo-cofactor [11-13]. Reaction with superoxide generates a high-valent $\mathrm{Mn}_{2}^{\text {III/IV }}$ intermediate state which decays to produce the tyrosyl radical (Y.) and an $\mathrm{Mn}_{2}^{\text {III/III }}$ metal site [10]. While the di-manganese cofactor appears to be the physiologically relevant form of class Ib R2 proteins, they can also function using a di-iron site via direct oxidation by molecular oxygen, resulting in an $\mathrm{Fe}_{2}^{\mathrm{III} / \mathrm{III}}$ metal site and $\mathrm{Y} \cdot[11,14]$.

Here, we report several high-resolution crystal structures of B. anthracis $\mathrm{NrdF}$ in the metal-free (apo) form, as well as the $\mathrm{Fe}$ - and $\mathrm{Mn}$-containing forms in the reduced state, prepared for reaction with molecular oxygen or superoxide, respectively. We also report the structure of a partially oxidized $\mathrm{Fe}$-containing protein after reaction with molecular oxygen. The latter structure reveals dynamics of a helical segment proximal to the metal site. Such dynamics are a characteristic feature of the oxygen-dependent R2 proteins and we hypothesize that they play an important role in tyrosyl radical turnover and stability. Considering that $B$. anthracis poses a risk of being used as a biological weapon, the structures may serve as a basis for drug design against this pathogen.

\section{Materials and methods}

\section{Materials}

Escherichia coli strains DH5 $\alpha$ (Stratagene) and Rosetta (DE3) (Novagen) were used for cloning and protein expression, respectively. Wild-type $B$. anthracis STERNE $7700 \mathrm{pXO1}-/ \mathrm{pXO} 2^{-}$(lacking both virulence plasmids) was obtained from the Swedish Defence Research Agency. $E$. coli strains were routinely grown in LB medium at $37^{\circ} \mathrm{C}$, and B. anthracis was grown in Brain Heart Infusion medium (Becton-Dickinson) at $37{ }^{\circ} \mathrm{C}$. When required, antibiotics and chromogenic substrates were added at the following concentrations: ampicillin $50 \mu \mathrm{g} / \mathrm{mL}$, chloramphenicol $20 \mu \mathrm{g} / \mathrm{mL}$, kanamycin $50 \mu \mathrm{g} / \mathrm{mL}$, and 5-bromo4-chloro-3-indolyl- $\beta$-D-galactopyranoside (X-Gal) $30 \mu \mathrm{g} /$ $\mathrm{mL}$. Genomic DNA from B. anthracis was extracted using the DNeasy tissue kit (Qiagen) according to the manufacturer's instructions.

\section{Cloning of B. anthracis NrdF, protein expression and purification}

The $n r d F$-coding sequence (UniProt: Q81TB4) was amplified by PCR using the genomic DNA of $B$. anthracis STERNE 7700 and the following primers: BaNrdF_For, 5'-ATACATATGCGTGCGGTAAACTGG-3', and BaNrdF_Rev 5'-ATAAAGCTTAAAAATTAAACACGAAGT CATC - $3^{\prime}$, introducing NdeI and HindIII restriction sites (underlined) at the start and at the end of the amplification product, respectively. The purified PCR product was cloned into plasmid pGEM-T easy (Promega), giving the plasmid pETS137. After digestion with NdeI and HindIII (Fermentas), the $n r d F$ fragment was ligated into pET22b (Novagen), resulting in a non-tagged full-length construct in pETS145. The pETS145 plasmid was further transformed into E. coli Rosetta (DE3) for protein expression. $B a \mathrm{NrdF}$ was purified as previously described (Ref. [15]) with two additional steps after Q-Sepharose chromatography. Particularly, Q-Sepharose protein fractions containing $B a \mathrm{NrdF}$ were incubated with $10 \mathrm{mM}$ EDTA and $2.5 \mathrm{mM}$ sodium dithionite on ice for $1.5 \mathrm{~h}$ and re-chromatographed on a HiLoad Superdex 200 16/60 pg (GE Healthcare) at a rate of $1 \mathrm{~mL} / \mathrm{min}$ in $20 \mathrm{mM}$ Tris- $\mathrm{HCl}$ pH 7.6 and $100 \mathrm{mM} \mathrm{KCl.} \mathrm{Ba} \mathrm{NrdF}$ protein fractions were checked by SDS-PAGE, pooled, and concentrated to $30 \mathrm{mg} / \mathrm{mL}$ using Centriprep-30 tubes (Millipore), flash cooled in liquid $\mathrm{N}_{2}$, and stored at $-80{ }^{\circ} \mathrm{C}$ until further use. 


\section{Total reflection X-ray fluorescence spectrometry (TXRF)}

Metal contents of the apoprotein preparation were quantified using TXRF analysis on a Bruker PicoFox instrument [16]. A gallium standard (Sigma) was added to duplicate samples (v/v 1:1) prior to the measurements. TXRF spectra were analyzed using the routines provided with the spectrometer.

\section{Crystallization and crystallographic data collection}

Apo $B a \mathrm{NrdF}$ was crystallized in hanging drop vapor diffusion experiments. Drops containing $1.5 \mu \mathrm{L}$ of protein at $10-12 \mathrm{mg} / \mathrm{mL}$ in $0.02 \mathrm{M}$ Tris buffer $\mathrm{pH} 7.6$ and $0.1 \mathrm{M}$ $\mathrm{KCl}$ were mixed with equal volumes of reservoir solution containing $1.8 \mathrm{M}$ or $2.0 \mathrm{M}$ ammonium sulphate and $0.1 \mathrm{M}$ Bis-Tris methane buffer, $\mathrm{pH} 6.5$, at $20^{\circ} \mathrm{C}$. Crystals grew within a few days. Larger crystals suitable for data collection, measuring approximately $0.2 \times 0.1 \times 0.1 \mathrm{~mm}$, were produced by streak seeding of fresh drops containing $1.5 \mu \mathrm{L}$ of protein at $4-6 \mathrm{mg} / \mathrm{mL}$ and $2-3 \mu \mathrm{L}$ of reservoir solution. Crystals were cryo-protected by transferring briefly to a solution of 3.4 M sodium malonate, $\mathrm{pH} 6.5$, and flash cooled in liquid $\mathrm{N}_{2}$ prior to data collection.

Apo $B a$ NrdF crystals were soaked in air-saturated mother liquor additionally containing freshly prepared $5 \mathrm{mM}$ $\mathrm{MnCl}_{2}$ or $\left(\mathrm{NH}_{4}\right)_{2} \mathrm{Fe}\left(\mathrm{SO}_{4}\right)_{2}$ for 20-30 min to obtain metalbound crystals. In the presence of $\mathrm{O}_{2}$ and $\mathrm{Fe}^{\mathrm{II}}$, the metal center formed should activate, leading to generation of the $\mathrm{Y}$, while the Mn-bound form is not expected to react with $\mathrm{O}_{2}$. These crystals were briefly washed in $3.4 \mathrm{M}$ sodium malonate, $\mathrm{pH}$ 6.5, and flash cooled in liquid nitrogen prior to data collection. To obtain the non-activated reduced diiron cofactor, apo $B a \mathrm{NrdF}$ crystals were soaked in mother liquor additionally containing $5 \mathrm{mM}\left(\mathrm{NH}_{4}\right)_{2} \mathrm{Fe}\left(\mathrm{SO}_{4}\right)_{2}, 0.5 \%$ (w/v) sodium dithionite, $0.5 \mathrm{mM}$ phenosafranin, and $25 \%$ glycerol (v/v) for $1 \mathrm{~h}$ and flash cooled in liquid nitrogen prior to data collection [17]. A preliminary $B a \mathrm{NrdF}$ diffraction data set was collected at $-173{ }^{\circ} \mathrm{C}$ at I911-3/MAX II (Lund, Sweden). Diffraction data presented here were collected at $-173{ }^{\circ} \mathrm{C}$ at PX14.1/BESSY (Helmholtz Center Berlin, Germany), X06SA, and X06DA/SLS (Villigen, Switzerland).

\section{Structure determination, model building, and refinement}

Crystals of $B a \mathrm{NrdF}$ belong to space group P2 ${ }_{1}$, with cell dimensions as shown in Table 1 . The asymmetric unit contains one NrdF dimer, giving a Matthews coefficient [18,
19] of $2.13 \AA^{3} / \mathrm{Da}$ and a solvent content of $42.3 \%$. Data were processed using XDS [20] and programs from the CCP4 suite [21, 22].

A preliminary structure of the $B a \mathrm{NrdF}$ was solved by molecular replacement (MR) using the MR pipeline MrBUMP [23] with Molrep [24] as an MR engine. The dimer of NrdF from Corynebacterium ammoniagenes, PDB code $1 \mathrm{KGN}$ [25], with $46 \%$ sequence identity to $B a \mathrm{NrdF}$, was successful as search model after side-chain truncation using Molrep [26]. After structure refinement in Refmac [27] and rebuilding using Coot [28], it was apparent that the metal site was partially metal-occupied. Thus, an additional de-metallation step during purification was used for the further structural studies reported here.

The metal-free $B a$ NrdF structure was solved by Phaser (Phenix suite) as an MR engine [29, 30] using the partially metal-containing $B a \mathrm{NrdF}$ dimer (unpublished). After ensuring that the protein was not metal-contaminated, the apo $B a \mathrm{NrdF}$ was used as an MR search model for the metalcontaining structures reported here. The models were iteratively rebuilt using Coot [28] and refined using phenix. refine [31]. Refinement generally included bulk solvent corrections, individual atomic coordinate and isotropic $B$ factor refinement, and occupancy refinement for alternate conformations. Metal-ligand bond restraints were used in the $\mathrm{Fe}_{2}$-semiox structure refinement to facilitate correct placement of alternative metal-chelating ligand conformations and solvent molecules at the metal sites; in the other structures, the metal-ligand bonds were not restrained. In the $\mathrm{Fe}_{2}$-aer and $\mathrm{Mn}_{2} B a \mathrm{NrdF}$ structures, anisotropic $B$ factors were refined (including metal ions) due to the sufficiently high resolution of the data (1.32 and $1.30 \AA$, respectively). Solvent molecules were added with phenix.refine and manually. Structures were validated using MolProbity [32]. Refinement and model quality statistics are presented in Table 1. Structure figures were prepared in PyMOL [33]. The homodimer-forming interaction surface was calculated using the manganese-bound $B a \mathrm{NrdF}$ structure and the PDBsum tool [34].

\section{Results and discussion}

In vitro, class Ib $\mathrm{NrdF}$ self-assembles to the $\mathrm{Fe}^{\mathrm{III}} / \mathrm{Fe}^{\mathrm{III}}$ tyrosyl radical-containing form in the presence of $\mathrm{Fe}^{\mathrm{II}}$ ions and dioxygen. The Mn-containing NrdF is likely the most relevant form in vivo, with the $\mathrm{Mn}^{\mathrm{III}} / \mathrm{Mn}^{\mathrm{III}}$-tyrosyl radical as its active state [35-38]. The protein self-assembles to the $\mathrm{Mn}^{\mathrm{II}} / \mathrm{Mn}^{\mathrm{II}}$ form in the presence of $\mathrm{Mn}^{\mathrm{II}}$ ions, but does not generate the tyrosyl radical, because it does not react directly with molecular oxygen. If metals are removed, $B a$ 
Table 1 Data collection and refinement statistics

\begin{tabular}{|c|c|c|c|c|c|}
\hline & Apo & $\mathrm{Fe}_{2}$-aer & $\mathrm{Fe}_{2}$-anox & $\mathrm{Mn}_{2}$ & $\mathrm{Fe}_{2}$-semiox \\
\hline PDB ID & 6QO5 & 6QO7 & 6QO8 & 6QO9 & 6QOB \\
\hline \multicolumn{6}{|l|}{ Data collection statistics } \\
\hline Wavelength $(\AA)$ & 0.92 & 0.92 & 0.92 & 0.92 & 1.00 \\
\hline Resolution range $(\AA)$ & $\begin{array}{l}40.35-1.51 \\
(1.57-1.51)\end{array}$ & $\begin{array}{l}41.82-1.63 \\
(1.69-1.63)\end{array}$ & $\begin{array}{l}42.26-1.32 \\
(1.37-1.32)\end{array}$ & $\begin{array}{l}27.58-1.30 \\
(1.35-1.30)\end{array}$ & $\begin{array}{l}45.93-1.46 \\
(1.51-1.46)\end{array}$ \\
\hline Space group & $\mathrm{P} 2{ }_{1}$ & $\mathrm{P} 2{ }_{1}$ & $\mathrm{P} 2{ }_{1}$ & $\mathrm{P} 2{ }_{1}$ & $\mathrm{P} 2{ }_{1}$ \\
\hline $\begin{array}{l}\text { Unit cell dimensions } \\
\text { a, b, c }(\AA)\end{array}$ & $57.19,59.81,95.23$ & $57.29,59.96,95.36$ & $57.56,61.46,95.79$ & $57.53,61.23,95.84$ & $57.14,60.38,95.76$ \\
\hline $\begin{array}{l}\text { Unit cell dimensions } \\
\beta\left(^{\circ}\right)\end{array}$ & 107.08 & 107.11 & 106.59 & 106.48 & 106.38 \\
\hline Unique reflections & $95,740(9403)$ & $77,058(7581)$ & $147,577(13,178)$ & $155,351(15,233)$ & $107,862(9731)$ \\
\hline Multiplicity & $3.7(3.8)$ & $3.8(3.8)$ & $3.2(2.3)$ & $3.3(3.3)$ & $3.4(3.0)$ \\
\hline Completeness (\%) & $99.46(97.94)$ & $99.61(98.35)$ & $97.86(87.89)$ & $99.00(97.65)$ & $98.67(89.12)$ \\
\hline Mean I/sigma (I) & $16.35(2.11)$ & $12.80(2.05)$ & $14.70(1.75)$ & $14.90(2.16)$ & $11.48(1.62)$ \\
\hline Wilson B factor $\left(\AA^{2}\right)$ & 18.59 & 19.44 & 12.83 & 10.77 & 15.61 \\
\hline R-merge & $0.044(0.622)$ & $0.062(0.628)$ & $0.040(0.437)$ & $0.048(0.532)$ & $0.058(0.584)$ \\
\hline $\mathrm{R}$-meas & $0.051(0.723)$ & $0.072(0.729)$ & $0.048(0.559)$ & $0.057(0.632)$ & $0.069(0.710)$ \\
\hline R-pim (I) & $0.0261(0.365)$ & $\begin{array}{l}0.036 \\
(0.366)\end{array}$ & $\begin{array}{l}0.026 \\
(0.343)\end{array}$ & $\begin{array}{l}0.031 \\
(0.338)\end{array}$ & $\begin{array}{l}0.037 \\
(0.399)\end{array}$ \\
\hline $\mathrm{CC}_{1 / 2}$ & $0.999(0.805)$ & $0.999(0.778)$ & $0.999(0.817)$ & $0.999(0.796)$ & $0.999(0.746)$ \\
\hline \multicolumn{6}{|l|}{ Refinement statistics } \\
\hline Reflections used in refinement & $\begin{array}{l}95,758 \\
(9403)\end{array}$ & $\begin{array}{l}77,191 \\
(7581)\end{array}$ & $147,262(13,165)$ & $\begin{array}{l}155,158 \\
(15,228)\end{array}$ & $107,820(9731)$ \\
\hline Reflections used for R-free & $4788(470)$ & $3860(379)$ & $7360(657)$ & $7756(761)$ & $5391(486)$ \\
\hline R-work & $0.17(0.27)$ & $0.16(0.28)$ & $0.13(0.21)$ & $0.14(0.19)$ & $0.17(0.28)$ \\
\hline R-free & $0.19(0.30)$ & $0.19(0.30)$ & $0.16(0.24)$ & $0.16(0.21)$ & $0.19(0.28)$ \\
\hline Protein residues & 580 & 579 & 574 & 576 & 575 \\
\hline Number of non-hydrogen atoms & 5078 & 5069 & 5371 & 5385 & 5194 \\
\hline Number of water molecules & 305 & 317 & 546 & 492 & 357 \\
\hline Number of metal ions & 0 & 4 & 4 & 4 & 4 \\
\hline RMS, bonds $(\AA)$ & 0.013 & 0.013 & 0.011 & 0.012 & 0.012 \\
\hline RMS, angles $\left({ }^{\circ}\right)$ & 1.20 & 1.18 & 1.13 & 1.44 & 1.17 \\
\hline Ramachandran favored (\%) & 98.95 & 99.12 & 99.12 & 99.13 & 98.95 \\
\hline Ramachandran allowed (\%) & 1.05 & 0.88 & 0.88 & 0.87 & 1.05 \\
\hline Ramachandran outliers (\%) & 0.00 & 0.00 & 0.00 & 0.00 & 0.00 \\
\hline Rotamer outliers (\%) & 0.39 & 0.39 & 0.00 & 0.19 & 0.00 \\
\hline Clashscore & 1.68 & 1.90 & 1.67 & 1.95 & 3.95 \\
\hline Average B factor $\left(\AA^{2}\right)$ & 24.13 & 25.36 & 18.08 & 16.73 & 20.22 \\
\hline
\end{tabular}

Statistics for the highest resolution shell are shown in parentheses

$R M S$ root mean square

$\mathrm{NrdF}$ remains stable in vitro and is capable of forming a dinuclear $\mathrm{Fe}$ or $\mathrm{Mn}$ cofactor in the presence of the respective divalent metal ions.

Here, we present five structures of class Ib B. anthracis $\mathrm{NrdF}$ derived from apo protein and loaded with $\mathrm{Mn}^{\mathrm{II}}$ or $\mathrm{Fe}^{\mathrm{II}}$ under anoxic or aerobic conditions after crystallization. The crystal structures were determined to high resolution (refer to Table 1 for data quality and refinement statistics). The structures are abbreviated as follows: metal-free $B$. anthracis
$\mathrm{NrdF}$ - apo $B a \mathrm{NrdF}, \mathrm{Fe}$-loaded protein in the presence of oxygen- $\mathrm{Fe}_{2}$-aer $B a \mathrm{NrdF}, \mathrm{Fe}-$ loaded protein in the absence of oxygen- $\mathrm{Fe}_{2}$-anox $\mathrm{Ba \textrm {NrdF }}, \mathrm{Mn}$-loaded protein in the presence of oxygen- $\mathrm{Mn}_{2} \mathrm{Ba} \mathrm{NrdF}$, and the structure of $\mathrm{Fe}-$ containing $B a \mathrm{NrdF}$ prepared in the presence of oxygen and exposed to a highly attenuated $\mathrm{X}$-ray beam $-\mathrm{Fe}_{2}$-semiox $\mathrm{Ba}$ NrdF.

Prior to protein crystallization and metal-soaking experiments, the $B a \mathrm{NrdF}$ protein solution was analyzed by TXRF 
to ensure that it was metal-free. The content of manganese and iron as well as other transition metals ( $\mathrm{Ni}, \mathrm{Cu}$, and $\mathrm{Zn}$ ) in the sample was negligible ( $\leq 0.1$ metal per protein). For the structural analysis of $\mathrm{Ba} \mathrm{NrdF}$ in complex with iron or manganese prepared aerobically and anaerobically, crystals of apo protein were soaked with $\mathrm{Fe}^{\mathrm{II}}$ or $\mathrm{Mn}^{\mathrm{II}}$ salts (see "Methods" for details).

\section{Overall structures of B. anthracis NrdF}

The $B a$ NrdF is as a heart-shaped homodimer with a monomer-monomer interaction surface of about $2200 \AA^{2}$, mostly built by hydrophobic interactions and pronounced exchange of the N-termini between monomers. Each monomer comprises a helix bundle fold similar to other class Ib R2 proteins [39] (Fig. 1). All structures of $B a$ NrdF show well-defined electron density, except for the flexible polyglutamate region (E275-E278) in the loop connecting helices $\alpha \mathrm{H}$ and $\alpha 3$. The last 34 residues of the C-terminus, important for interaction with the catalytic subunit R1 [39], are disordered, with the exception of apo and $\mathrm{Fe}_{2}$-aer $\mathrm{Ba}$ $\mathrm{NrdF}$, where seven extra residues of the C-terminus form an additional small helix. Globally, the apo $B a N r d F$ and the Feor Mn-containing forms are almost identical, with the largest RMSD value of $0.25 \AA$ over all $\mathrm{C}_{\alpha}$ atoms, compared to apo $B a \mathrm{NrdF}$. Interestingly, the structures reveal two proline residues, unusually located within a helix while not breaking the helical secondary structure. The first proline residue, P71, is located on $\alpha \mathrm{B}$ at the core of a dimer interface. The second

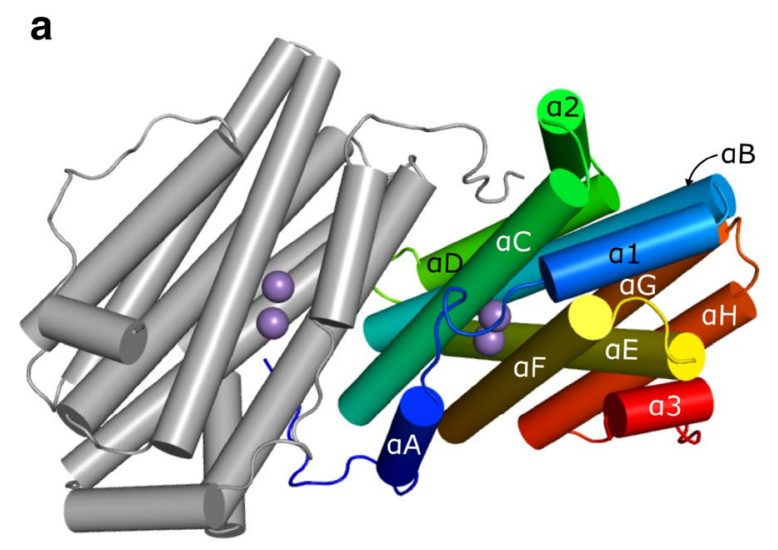

Fig. 1 Overall architecture of the B. anthracis NrdF homodimer. a Cartoon representation of the manganese-bound $\mathrm{Ba}$ NrdF homodimer. Helices are shown as cylinders and colored in rainbow (blue: N-terminus; red: C-terminus) in one of the protein subunits; the other subunit is shown in grey. The manganese ions in the di-nuclear metal proline residue, $\mathrm{P} 172$, is localized on $\alpha \mathrm{E}$ in the vicinity of the conserved metal-binding site.

\section{Structures of the apo and metal-loaded B. anthracis NrdF metal sites}

The metal-binding site of each subunit of $B a \mathrm{NrdF}$ consists of two histidines (H96 and H198) and four carboxylate ligands conserved in class Ia and Ib R2 proteins (D62, E93, E161, and E195), located in the core of the helix bundle of each protomer on helices $\alpha \mathrm{B}, \alpha \mathrm{C}, \alpha \mathrm{E}$, and $\alpha \mathrm{F}$ (Fig. 1a, b). Notably, in class Ic and Id orthologs, the first carboxylate (D62 in $\mathrm{Ba}$ ) is a glutamic acid, whereas in the newly discovered class Ie, three of the carboxylates are substituted, precluding metal binding $[4,5,8]$. Structures of the $B a \mathrm{NrdF}$ metal sites are shown in Fig. $2 \mathrm{a}-\mathrm{d}$.

In the apo structure, a water molecule, hydrogen bonded to D62, H96 and E195, occupies metal site 1, proximal to the radical-carrying residue Y100. Metal site 2, in turn, is vacant, with E161, H198, and E195 forming an H-bond network. Notably, the conformation of E195 seems to be stabilized by hydrogen bonds with E93 and E161, resulting in very short $\mathrm{H}$-bond distances between these residues, refining to $2.4 \AA$. In addition, E161 is hydrogen bonded to a water molecule (Fig. 2a).

The structures of the reduced metal-binding sites in $\mathrm{Fe}_{2}$-anox and $\mathrm{Mn}_{2}$-bound $\mathrm{Ba} \mathrm{NrdF}$ are identical within experimental error in terms of the metal ligand conformation and hydrogen-bonding pattern: the metal ions in sites 1 and 2 are 4- and 5-coordinated, respectively, with a typical

b

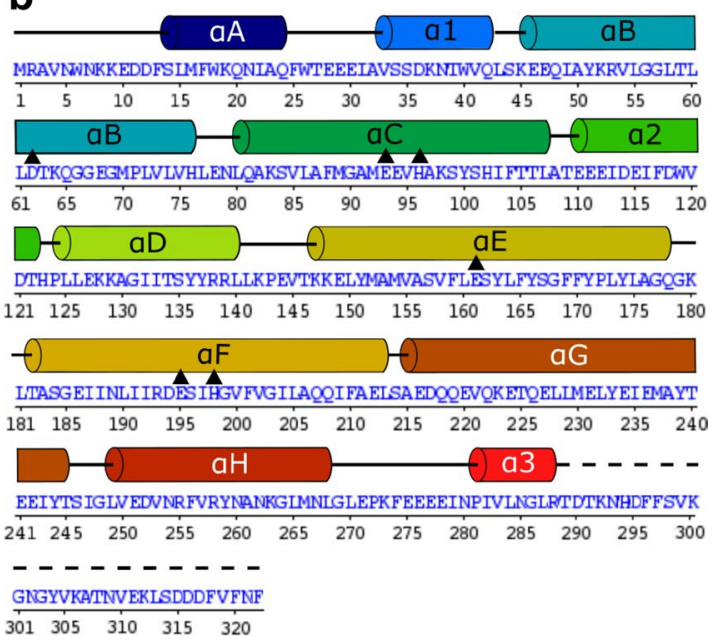

centers are shown as purple spheres. Helix nomenclature is adapted from Ref. [40]. b Sequence of $B a \mathrm{NrdF}$ with aligned secondary structure. Metal-binding residues are indicated as black triangles. Dashed lines indicate parts of the structure that were not resolved in the electron density 


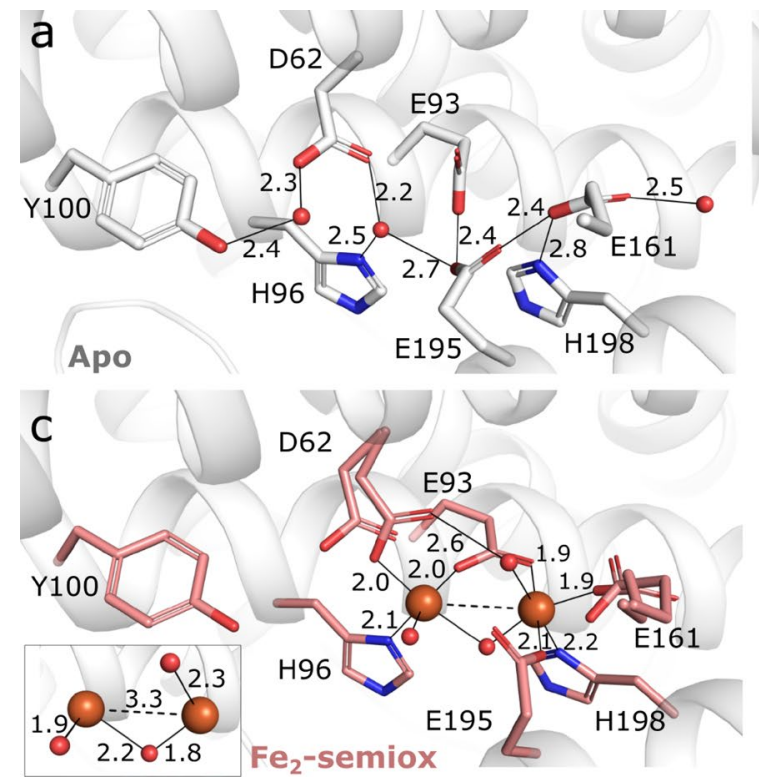

Fig. 2 Coordination environment of $B a \mathrm{NrdF}$ metal sites in different metalation and oxidation states. a Metal site of the apo $B a \mathrm{NrdF}$. b Overlay of the $\mathrm{Fe}_{2}$-aer (green), $\mathrm{Fe}_{2}$-anox (yellow) and $\mathrm{Mn}_{2} \mathrm{Ba} \mathrm{NrdF}$ (wheat) metal sites representing reduced states. The positions of manganese (II) and ferrous ions as well as Y100 in $\mathrm{Mn}_{2}$ and $\mathrm{Fe}_{2}$-anox structures superpose perfectly. A low occupancy solvent molecule coordinating Y100 was omitted for clarity. c Metal-chelating ligands D62, E161, and E195 in the oxygen-activated $\mathrm{Fe}_{2}$-semiox structure represent a transition from oxidized to reduced coordination modes.

bond length of 1.9-2 $\AA$ (Fig. 2b). The metal in site 1 has three monodentate carboxylate ligands: D62, E93, and E195, and an additional bond to H96. The metal in site 2 also has two monodentate carboxylate ligands, E93 and E195, and an additional bond to H198. E161 coordinates the metal ion in site 2 in a bidentate fashion; however, one of the carboxylateto-metal distances is somewhat longer. Despite the expected metallo-cofactor activation by oxygen in the $\mathrm{Fe}_{2}$-aer crystal, there is no evidence of a $\mu$-aqua, hydroxo, or oxo bridge, and the metal site seems to represent a reduced state, as judged by the conformation of the metal-coordinating ligands, the metal-metal distance $(3.9 \AA$ ), and the fact that the structure of the metal site is within experimental error identical to the reduced di-manganese and $\mathrm{Fe}_{2}$-anox (di-ferrous) structures (Fig. 2b). Given the high sensitivity of R2 proteins to X-ray photo-reduction [41], a property that appears particularly pronounced in class Ib proteins [25, 42, 43], the metallo-cofactor of the $\mathrm{Fe}_{2}$-aer structure was most likely photo-reduced during $\mathrm{X}$-ray data collection. Interestingly, the redox-active Y100 side chain displays a dual conformation. It is particularly well defined in both fully reduced structures- $-\mathrm{Fe}_{2}$-anox and $\mathrm{Mn}_{2}$ $\mathrm{Ba} \mathrm{NrdF}$, and to a lesser extent in the $\mathrm{Fe}_{2}$-aer structure. To our knowledge, this feature has not been previously reported for class Ib R2 proteins (discussed further below).

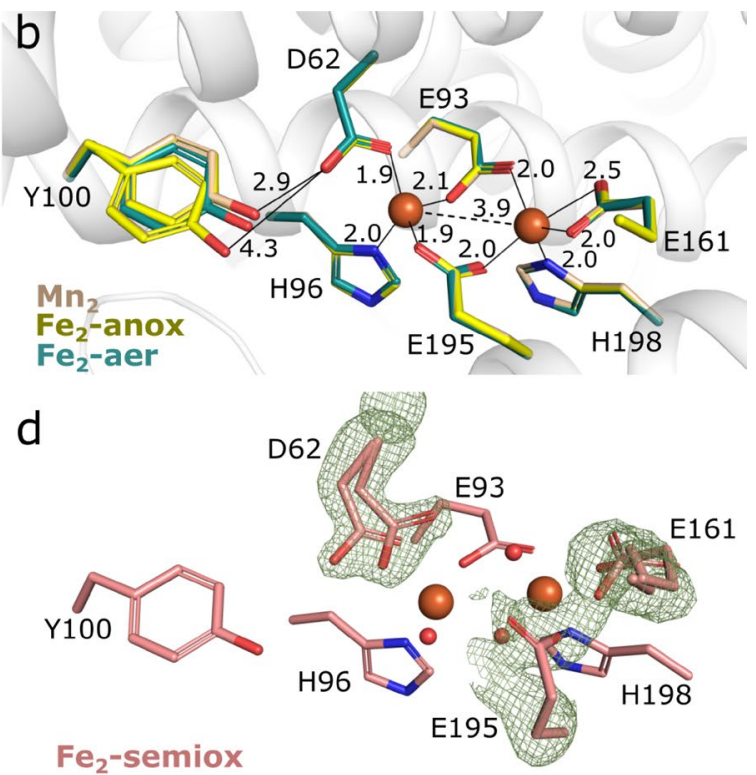

The insert shows the aqua-bridged di-ferric metallo-cofactor with an additional water molecule coordinating each metal ion. d Omit $F_{\mathrm{o}}-F_{\mathrm{c}}$ electron density map (green mesh) around D62, E161, and E195 in $\mathrm{Fe}_{2}$-semiox structure illustrating their conformational flexibility. The map is contoured at $3.5 \sigma$ and shown within a $1.6 \AA$ radius from these residues. Solid lines indicate hydrogen or ionic bonds and dashed lines indicate metal-metal distances (in $\AA$ ). Water molecules are shown as small spheres and metal ions are shown as large spheres

Finally, we attempted to obtain a structure of $B a \mathrm{NrdF}$ with an oxidized metallo-cofactor. Apo $B a \mathrm{NrdF}$ crystals were soaked with ferrous salt in the presence of oxygen and exposed to a highly attenuated X-ray beam for data collection to decrease the effect of photo-reduction. The resulting structure $\left(\mathrm{Fe}_{2}\right.$-semiox) mainly displays structural features of the oxidized metallo-cofactor in both chains of the dimer, although it is obvious that photo-reduction was not completely avoided. Compared to the fully (photo-) reduced $B a \mathrm{NrdF}$ structures, the metal ions in both metal centers of the $\mathrm{Fe}_{2}$-semiox structure are linked by a monoatomic bridge, cis side relative to the metal-coordinating histidines, and the metal-metal distance is decreased to $3.3 \AA$. In addition, one solvent molecule coordinates to each $\mathrm{Fe}$ ion. Upon oxidation, the coordination pattern of the carboxylate ligands also changes. D62 is still monodentate to $\mathrm{Fe}$ in site 1, yet further away from Y100 compared to the reduced state. E161 and E195, on the other hand, appear to switch to a monodentate coordination to the $\mathrm{Fe}$ ion in site 2 , as evident from the shape of the $F_{\mathrm{o}}-F_{\mathrm{c}}$ omit difference electron density (Fig. 3c). E93 remains in a bidentate coordination mode, bridging both metal ions. Despite the partial occupancy of a reduced site, the oxidized structure could be modeled. In the oxidized structure, the $\mathrm{Fe}$ ion in site 1 is five-coordinate, while the ion in site 2 is six-coordinate. The structure thus appears similar to the di-ferric Escherichia coli $(E c)$ class Ia 


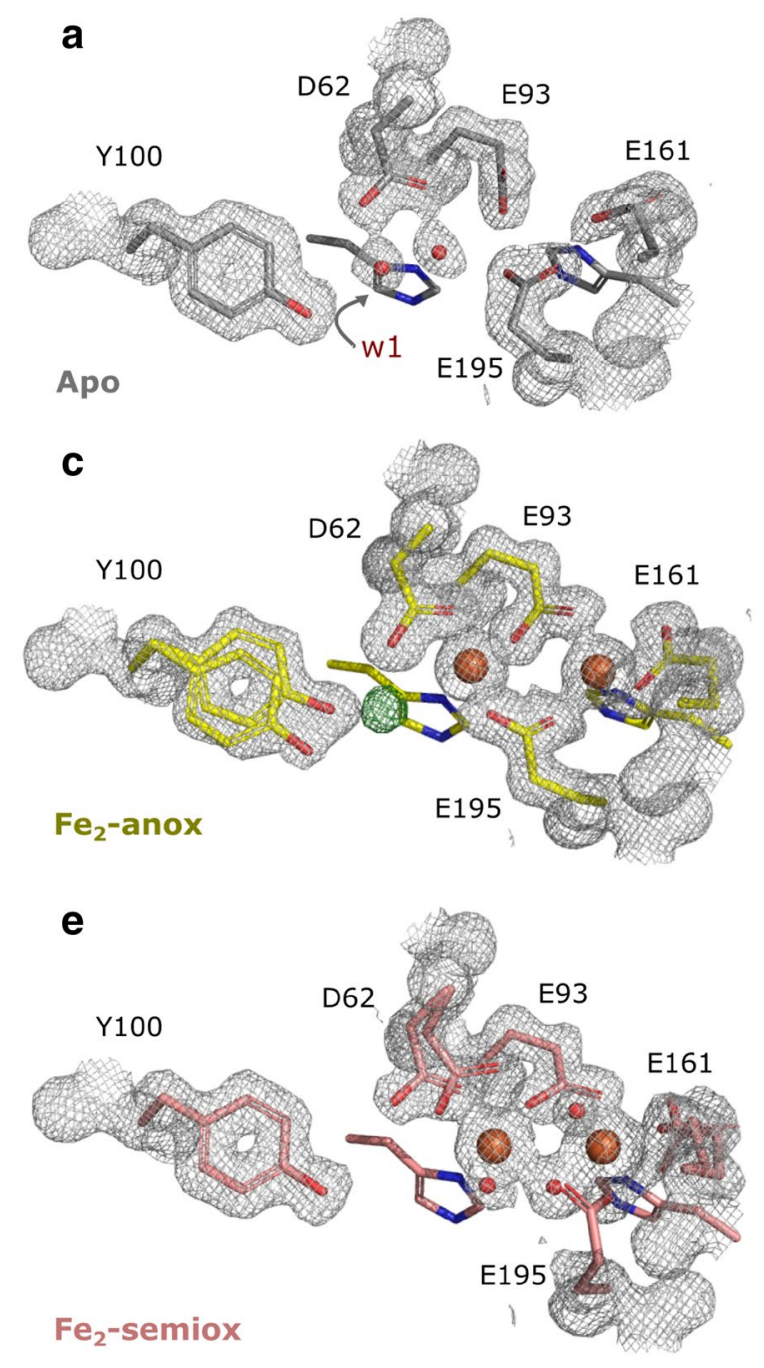

Fig. 3 Conformational dynamics of the redox-active tyrosine in $\mathrm{Ba}$ NrdF structures. a Metal site of the apo Ba NrdF. The Y100-B conformation is stabilized by a w1-mediated hydrogen bond to D62. b Metal site of the $\mathrm{Fe}_{2}$-aer $\mathrm{Ba} \mathrm{NrdF}$ in chain B. The Y100-B conformation is stabilized by a w1-mediated hydrogen bond to D62. The positive difference electron density map (green mesh) indicates that the alternative, Y100-A conformation is possible. c Metal site of the $\mathrm{Fe}_{2}$-anox $\mathrm{Ba} \mathrm{NrdF}$. The positive difference electron density map (green mesh) corresponds to solvent molecule w1. Y100 is modeled in two alternative conformations. d Metal site of the $\mathrm{Mn}_{2} \mathrm{Ba} \mathrm{NrdF}$. Y100 is modeled in two alternative conformations. The Y100-B conformation is stabilized by a w1-mediated hydrogen bond to D62. The hydroxyl group of Y100-A clashes with w1. e Metal site of the

NrdB and di-manganese (III) Corynebacterium ammoniagenes (Ca) $\mathrm{NrdF}$ in the resting (met) state [35, 44].

\section{Conformational variation of the redox-active tyrosine residue in B. anthracis NrdF structures}

Compared to the apo $\mathrm{Ba} \mathrm{NrdF}$, the metal-containing structures display a movement of the redox-active Y100
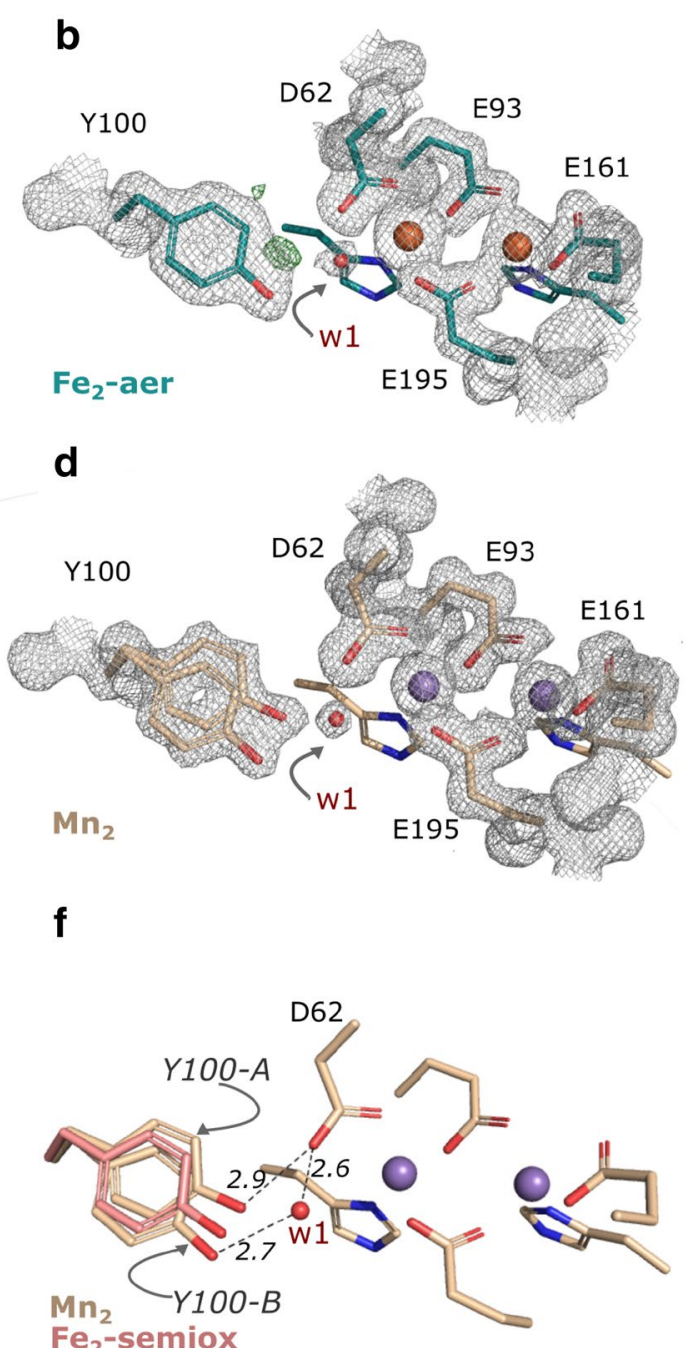

$\mathrm{Fe}_{2}$-semiox Ba NrdF. The position of $\mathrm{Y} 100$ refines as an average conformation between Y100-A and Y100-B. f Positional overlay of $\mathrm{Y} 100$ in $\mathrm{Fe}_{2}$-semiox and $\mathrm{Mn}_{2} \mathrm{Ba} \mathrm{NrdF}$ metal sites with highlighted differences between Y100-A and Y100-B conformations and the role of $w 1$ in stabilization of the conformation of Y100-B. Dashed lines indicate hydrogen bond distances (in $\AA$ ). The density map for H96 and H198 is not shown for clarity. The $2 F_{\mathrm{o}}-F_{\mathrm{c}}$ electron density map is contoured at $1.2 \sigma$ and shown as a grey mesh. The $F_{\mathrm{o}}-F_{\mathrm{c}}$ positive difference electron density map (green mesh) around Y100 is contoured at $3.2 \sigma$ and shown within a $1.6 \AA$ radius from the residue. Water/oxo/ hydroxo ligands are shown as red spheres. Metal ions are shown as larger spheres: $\mathrm{Fe}$ - in orange and $\mathrm{Mn}$ - in purple

relative to D62 and metal site 1 (Fig. 3a-f). Y100 in $\mathrm{Fe}_{2}$-aer, $\mathrm{Fe}_{2}$-anox, and $\mathrm{Mn}_{2}$-bound $\mathrm{Ba} \mathrm{NrdF}$ exists in a dual conformation (Y100-A and Y100-B). Previously reported highfield electron paramagnetic resonance (EPR) spectroscopy data on Fe-containing NrdF proteins from Salmonella typhimurium ( $S t), B a$ and $E c$ class Ia NrdB indicated a shift of the tyrosine (Y105 in $S t$ and Y122 in Ec) as a result of its oxidation to $\mathrm{Y} \cdot[15,44,45]$, resembling the conformational 
switch from Y100-A to Y100-B in our $B a$ NrdF structures (Fig. 3). However, given that $\mathrm{Fe}_{2}$-aer, $\mathrm{Fe}_{2}$-anox, and $\mathrm{Mn}_{2}$-bound $\mathrm{Ba} \mathrm{NrdF}$ clearly represent reduced states of the metallo-cofactors, attribution of the conformational change to $\mathrm{Y}$ - formation in this case appears implausible. Still, it is interesting to note that the tyrosine in $\mathrm{Ba} \mathrm{NrdF}$ exhibits conformational dynamics that may contribute to radical stabilization and initiation of radical transfer.

The Y100-B conformation appears to be stabilized by an adjacent water molecule $(w 1)$ found in the apo, $\mathrm{Fe}_{2}$-aer and $\mathrm{Mn}_{2}$-bound $B a \mathrm{NrdF}$ structures (Figs. 2a, 3a-d). The $w 1$ molecule bridges $\mathrm{Y} 100$ and D62 (Fig. 3f). In the $\mathrm{Fe}_{2}$-anox metallo-cofactor site, the $w 1$ is present at a low occupancy, as judged by the characteristic positive difference density peak in proximity to the split Y100 hydroxyls. The low occupancy of $w 1$ also appears to correlate with the occupancy of the Y100-B conformer in this structure (Fig. 3c). In the oxygen-activated $\mathrm{Fe}_{2}$-semiox structure $\mathrm{Y} 100$ refines best, within experimental error, as an average conformation between Y100-A and Y100-B (Fig. 3e, f) and no positive electron density corresponding to low-occupancy $w l$ can be observed. This conformational state of Y100 is potentially associated with subsequent decoupling from the metal site associated with the redox state-dependent shift of D62.

\section{Distorted topology of aE at the metal site}

$\alpha \mathrm{E}$ is one of the helices providing one of the six metalchelating ligands in R2 proteins, namely, E161 in Ba NrdF. In all our structures, as well as all other NrdF protein structures published to date, $\alpha$ E exhibits rather unusual distorted topology in close proximity to the metal site; within aminoacid stretch F159-Y171 ( $B a$ numbering). This region has both $\pi$-helical and $3_{10}$-helical features. As in all $\pi$-helices, the standard intra-helical hydrogen-bonding pattern $i+4$, characteristic for $\alpha$-helices, is disrupted by amino-acid insertions, causing a switch to $i+5$ (carbonyl of L160 to amide proton of F165 and carbonyl of F159 to amide proton of L164, as shown in Fig. 4a). In addition, a number of main chain carbonyl groups within $\alpha \mathrm{E}$ are not intra-helically hydrogen bonded. Particularly, the carbonyl group of E161, which participates in metal coordination of site 2 and was shown to be relatively flexible during metallo-cofactor oxidation-state changes, is hydrogen bonded to the Y166 hydroxyl, bridged by a solvent molecule. This is in agreement with what has been previously observed in $B$. subtilis class Ib R2 [46]. Similarly, through a water-mediated hydrogen bond, the main chain carbonyl group of S162 is linked to N260 and the carbonyl group of L164 is linked to E236. Finally, the main chain carbonyl of S167 directly interacts with Y244.

Several residues of $\alpha \mathrm{E}$ are hydrogen-bonded in an $i+3$ pattern, characteristic of $3_{10}$-type helices. These somewhat unusual hydrogen bonds occur between the carbonyl groups and amide protons, respectively, in the following residue pairs: Y163-Y166, F165-G168, and G168-Y171 (Fig. 4a). The intra-helical hydrogen-bonding pattern within the F159-Y171 amino-acid stretch does not change upon metal binding (specifically in the reduced and photo-reduced $\mathrm{Ba}$ $\mathrm{NrdF}$ structures) irrespective of the metal type bound.

\section{Structural rearrangements in aE upon oxidation of the di-iron metallo-cofactor in B. anthracis NrdF}

$\pi$-helices are often found close to protein functional sites and are energetically expensive [47]. This somewhat distorted region of the helix corresponding to $\alpha \mathrm{E}$ in $B a \mathrm{NrdF}$ is conserved in many ferritin superfamily members: class I R2 proteins, R2-like ligand-binding oxidases (R2lox), bacterial multicomponent monooxygenases (BMMs), and aldehyde-deformylating oxygenases (ADO) among others, suggesting a functional role $[48,49]$. The purpose of this high-energy conformation throughout the superfamily, however, is enigmatic.

The F159-Y171 helix segment in the $\mathrm{Fe}_{2}$-semiox structure undergoes conformational changes compared to the apo and reduced $B a \mathrm{NrdF}$ structures, as evident from the positive difference $F_{\mathrm{o}}-F_{\mathrm{c}}$ maps (Fig. $4 \mathrm{~b}-\mathrm{d}$ ). The dominant conformation of the F159-Y171 helix segment in the $\mathrm{Fe}_{2}$-semiox $B a$ $\mathrm{NrdF}$ is identical to that in the (photo-) reduced $\mathrm{Ba} \mathrm{NrdF}$ structures (Fig. 4a, c). To visualize the conformational changes and assess their possible role in protein function, we used the positive difference $F_{\mathrm{o}}-F_{\mathrm{c}}$ density map for building the alternative conformation of the $\alpha \mathrm{E}$ main chain and side chains, where possible (Fig. 4c, d; Supplementary Movie 1). Notably, the alternative conformation of the helix (Fig. 4e) is very similar to one reported by Cox et al. for the oxidized dimanganese $\mathrm{Ca} \mathrm{NrdF}$ (PDB ID: 3MJO) [35] (Supplementary Movie 2). The most dramatic conformational changes were observed for residues F165, Y166, and S167, all located on the apical side of the metal site. Particularly, S167 forms a new intra-helical hydrogen bond with the F170 backbone amide while losing a bond with the E236 carboxyl (located on $\alpha \mathrm{G}$ ) and causes Y166 to slide out significantly towards the $\alpha \mathrm{F}$ main chain. The F165 side chain capping the metal site flips and stacks against F169 and the radical-generating Y100. Similar conformational changes in $\alpha E$ have been previously described for Fe-containing $S t \mathrm{NrdF}$. Ericsson et al. propose a relation between the alternate conformation of $\alpha \mathrm{E}$ and metallo-cofactor oxidation states [50]. Cotruvo et al. [10] propose that $\alpha E$ may control a joint event of superoxide delivery from NrdI to NrdF and then trigger NrdI dissociation from the complex once the process is complete.

The timing of the conformational change of the $\alpha \mathrm{E}$ backbone is elusive. It is possible that the structural rearrangements are initiated by a carboxylate shift of E195 in 

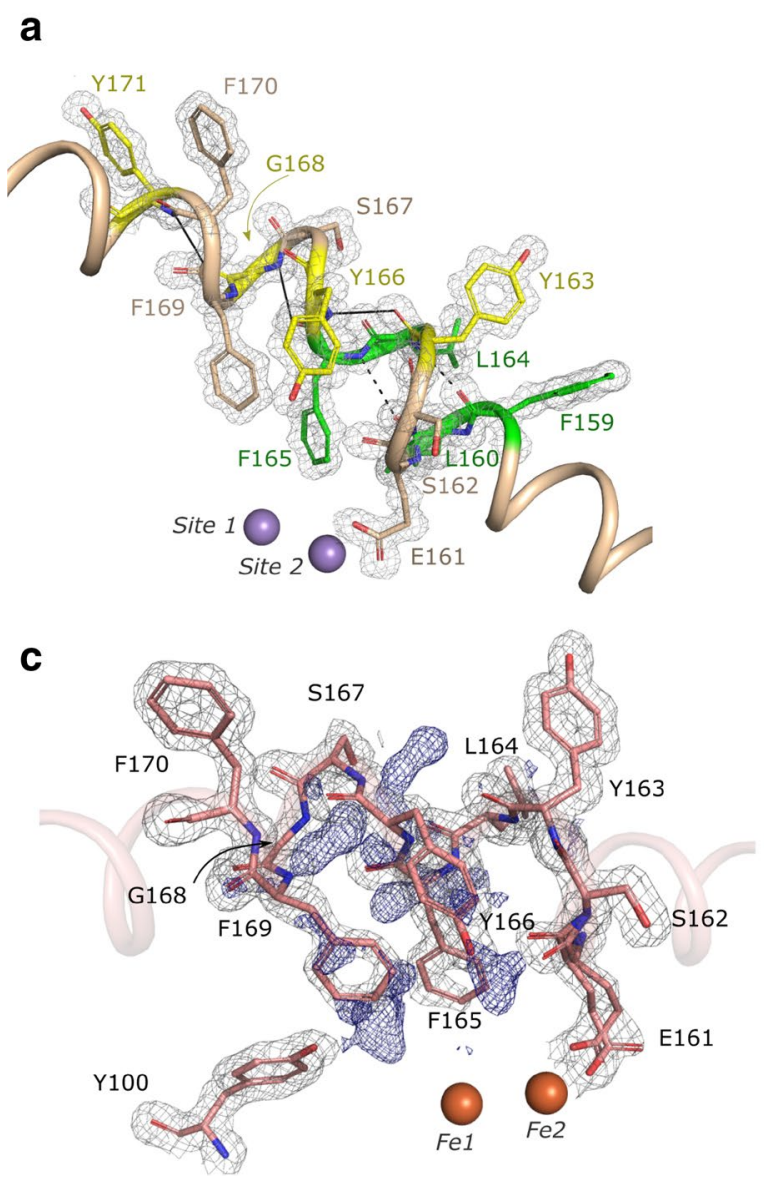

Fig. 4 Helix E undergoes structural rearrangements upon metallocofactor oxidation. a Residues participating in $i+5$ interactions are shown in green and the respective hydrogen bonds are shown as dashed black lines. The residues participating in $3_{10}$-type $(i+3)$ interactions are shown in yellow and the respective hydrogen bonds are shown as solid black lines. Metal ions (Me1 and Me2) are shown as spheres. b Cartoon illustration of conformational differences in $\alpha \mathrm{E}$ upon metallo-cofactor oxidation in the $\mathrm{Ba} \mathrm{Fe}_{2}$-semiox structure. The $\alpha \mathrm{E}$ conformation corresponding to the reduced state is highlighted in blue, oxidized-in red. Chain B of the $B a \mathrm{NrdF}$ heterodimer is hid-

response to metallo-cofactor activation. However, it cannot be excluded that this process is triggered earlier by the superoxide interaction with the hydrophilic channel [10] or the water molecule stabilizing the reduced $\pi$-helix conformation [46]. Once E195 flips and changes to monodentate coordination to the Fe ion in site 2 (Fig. 2b-d), its liberated oxygen stacks against the phenyl ring of F165. Consequently, the F165 side chain flips, as evident from the incomplete $2 F_{\mathrm{o}}-F_{\mathrm{c}}$ electron density around the F165 phenyl ring (Supplementary Fig. 1a). Once flipped, F165 then stacks against the strictly conserved F169, possibly forming aromatic interactions between the phenyl rings. Finally, the F169 side chain, together with F165, closes the hydrophobic pocket around Y100 from the apical side of the metal site. b
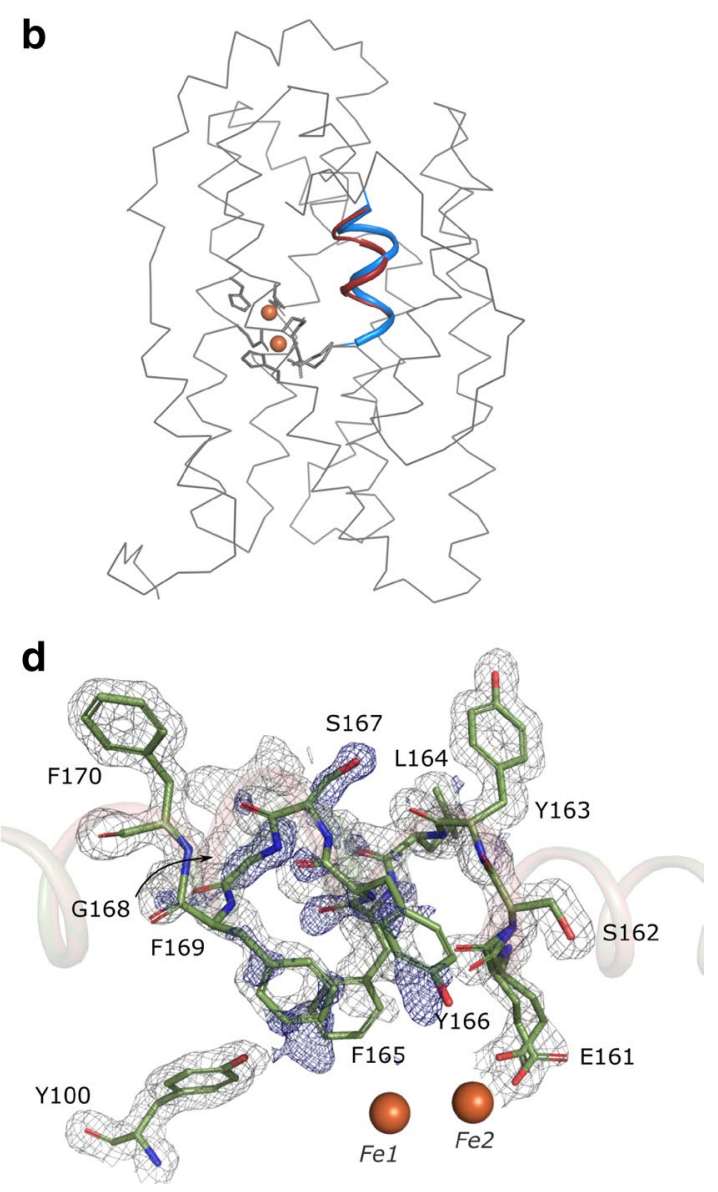

den for clarity. $\mathbf{c} \alpha \mathrm{E}$ kink in $\mathrm{Ba} \mathrm{Fe}_{2}$-semiox is modeled as in (photo-) reduced structures; however, positive difference electron density (shown as blue mesh) suggests structural rearrangements upon oxidation. $\mathbf{d}$ Model of $\alpha \mathrm{E}$ rearrangements upon metallo-cofactor oxidation, as suggested by positive $F_{\mathrm{o}}-F_{\mathrm{c}}$ electron density. The $2 F_{\mathrm{o}}-F_{\mathrm{c}}$ electron density map is contoured at $1.2 \sigma$ and shown as a grey mesh within $1.2 \AA$ radius from the residues. The $F_{\mathrm{o}}-F_{\mathrm{c}}$ electron density map is contoured at $2.5 \sigma$ and shown as a blue mesh within $2.0 \AA$ radius from the residues

The residue in position $169(B a)$ is strictly conserved as phenylalanine in R2 proteins (F166 in $E c$ and $S t$; F176 in $C a$, F169 in Bacillus cereus $(B C)$ and even in the newly discovered class Ie NrdF proteins $[4,5]$ ) and may play an important role in shielding the radical site, thus contributing to its stability and potentially mobilization for delivery to protein $\mathrm{R} 1$. The side chain corresponding to $\mathrm{F} 165$, on the other hand, is conserved as phenylalanine or leucine in $\mathrm{R} 2$ proteins and caps the metal site on the side, where the reaction with oxidant is expected to take place. It appears plausible that this residue is involved in regulation of electron transfer between the redox-active tyrosine Y100 and the metal site. In addition, the F165-F169 side chain pair may be involved in preventing radical loss by closing the hydrophobic pocket 
around Y100. Interestingly, the $\mathrm{Mn}^{\mathrm{II}}$-bound $B c$ and $E c \mathrm{NrdF}$ structures also display rotation of the side chain equivalent to F165 in $B a$ (F165 in $B c$ and F162 in $E c$ ). Here, the phenylalanine flips to make space for the glutamate, corresponding to E161 in $B a$ (E161 in $B c$ and E158 in $E c$ ), which coordinates to both $\mathrm{Mn}$ ions on the trans side relative to the metal-coordinating histidine residues [12, 51]. However, no alternate conformations of $\alpha \mathrm{E}$ can be observed.

\section{The hydrophilic Nrdl-NrdF channel is closed when the metallo-cofactor is oxidized}

Class Ib R2 s have been shown to function as di-manganese proteins in vivo [35-38]. A flavin mononucleotide (FMN)containing activase, denoted NrdI and conserved in class $\mathrm{Ib}$ and Ie R2 proteins, was found to be essential for Mn-ion oxidation and subsequent $\mathrm{Y}$. generation, since $\mathrm{Mn}^{\mathrm{II}}$ generally does not react spontaneously with molecular oxygen [10]. The NrdF-NrdI complex forms a channel, connecting the FMN cofactor in NrdI with the metal site in NrdF, presumably utilized for delivery of the oxidant species to the $\mathrm{Mn}^{\mathrm{II}} / \mathrm{Mn}^{\mathrm{II}}$ cofactor [11-13]. NrdF-NrdI complex crystal structures are available for the orthologs from E. coli (dimanganese form) [12] and B. cereus (di-iron form) [51] with reduced metallo-cofactors in both structures. These NrdF proteins are $42 \%$ and $99 \%$ identical in sequence to $B a \mathrm{NrdF}$, respectively. Given the very high sequence similarity with $B c \mathrm{NrdF}$, the interaction surface with the $\mathrm{NrdI}$ and the FMN in $B a \mathrm{NrdF}$ can be presumed to be the same. Therefore, we docked the $B c \mathrm{NrdI}$ and $B a \mathrm{Fe}_{2}$-semiox NrdF. In the docking model, the likely solvent passage linking the FMN and the metal in site 2 in $\mathrm{NrdF}$ extends between helices $\alpha \mathrm{E}$ and $\alpha \mathrm{F}$ (Fig. 5). In addition, we compared our $B a \mathrm{NrdF}-\mathrm{NrdI}$ model to the crystallographically characterized native $E c$ NrdF-NrdI complex [12].

The $\mathrm{Fe}_{2}$-semiox $\mathrm{Ba} \mathrm{NrdF}$ electron density data, together with data reported by Cox et al. for oxidized di-manganese $\mathrm{Ca} \mathrm{NrdF}$, suggest that orchestrated conformational changes in the NrdF subunit are triggered by reaction with oxygen. Particularly, the carboxylate shift of E195 synchronized with changes in metal-metal distance and solvation cause choreographed movement of the $\alpha \mathrm{E}$ backbone in the $\mathrm{NrdF}$ subunit, likely initiated at the aromatic side chains (F165 and F169). The phenylalanine side chains flip and seal the hydrophobic pocket around the Y100 radical from the metallo-cofactor side. At the same time, adjustments of the aromatic residues cause significant intra-helical hydrogen bond rearrangements in the $\alpha \mathrm{E} \pi-/ 3_{10}$-helical region (Fig. 4), forcing Y166 to move towards $\alpha \mathrm{F}$ (at residue $\mathrm{S} 196$ ). It is not unlikely that Y166 and S196 (Y163-A193 in Ec and St, Y173-S203 in $\mathrm{Ca} \mathrm{NrdF}$ ) form a hydrogen bond, and the solvent passage is then sealed (Fig. 5 and Supplementary Movies 1 and 2). In fact, this hydrogen bond is evident in the oxidized di-iron $S t$

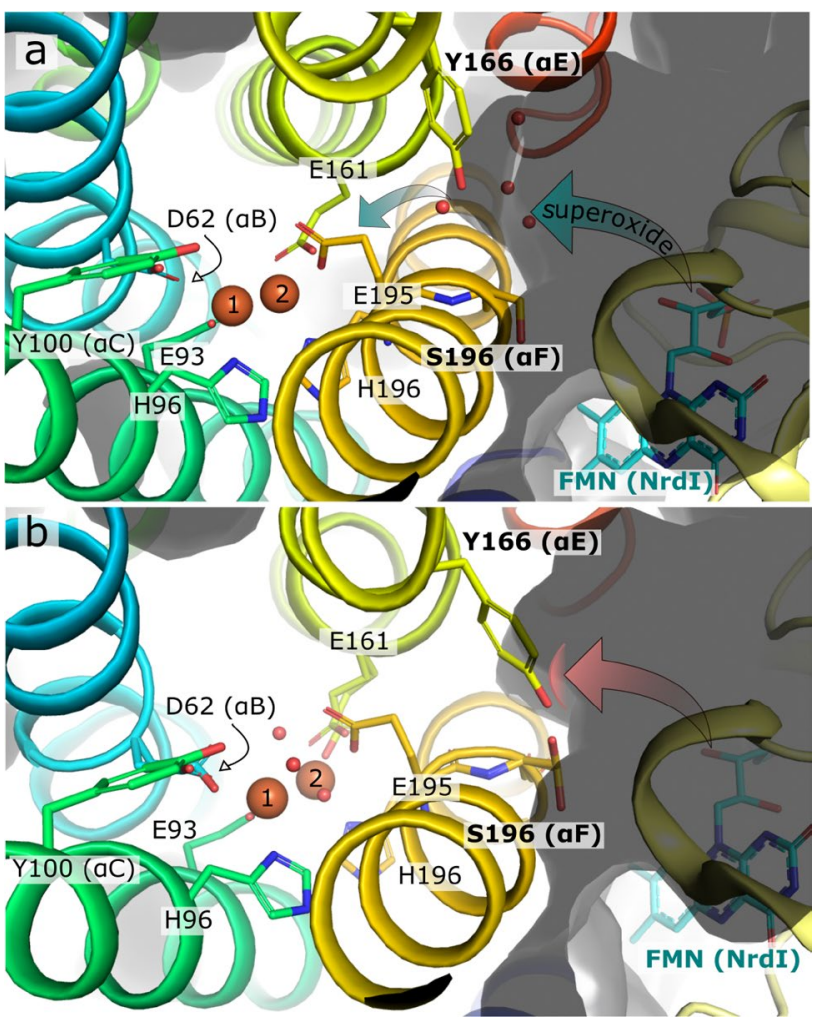

Fig. 5 Proposed gating of the NrdI-NrdF (FMN-metal cluster) solvent/oxidant channel. a Docked model of the FMN-bound NrdI and $\mathrm{Ba} \mathrm{Fe}_{2}$-semiox NrdF (based on the Bc complex, PDB id: 4BMO). A surface-slice view of the open solvent/superoxide channel (blue arrows), connecting the FMN cofactor and the metal cluster (modeled as reduced) of the $\mathrm{Ba} \mathrm{NrdF}$. b Upon oxidation of the metal cluster, the distorted $\alpha \mathrm{E}$ segment rearranges; Y166 seals the solvent/superoxide channel (red arrow) by making a polar interaction with $\alpha \mathrm{F}$. The helices of $\mathrm{Ba} \mathrm{NrdF}$ are colored, as shown in Fig. 1. Metal ions are shown as large orange spheres, FMN in cyan sticks. Residues gating the solvent access channel are labeled in bold. The protein surface is shown in translucent grey

and di-manganese $\mathrm{Ca} \mathrm{NrdF}$ (Ref. [35, 50]). In the absence of NrdI, Y166 is exposed to disordered surface solvent in all NrdF structures published to date; its hydroxyl-to $\alpha \mathrm{F}$ distance, therefore, varies. The side chain corresponding to Y166 in $B a$, together with other polar residues that line the solvent passage from the FMN to metal site 2, is conserved [12, 51].

In $E c$ NrdF complexed with NrdI (PDB ID: 3N39 and 3N3A), the solvent passage to the di-manganese metal appears to be open, which is in good agreement with the metallo-cofactor oxidation state in these crystal structures [12]. In Mn-loaded $E c \mathrm{NrdF}$, the aromatic side chain corresponding to $\mathrm{F} 165$ in $B a$ adopts an unusual conformation (F162 in $E c$ ), similar to the one in the oxidized $S t$ and $\mathrm{Ca}$ structures $[35,50]$ and resembling the proposed alternative conformation in $\mathrm{Fe}_{2}$-semiox $\mathrm{Ba} \mathrm{NrdF}$ (Fig. 4c, d). However, in the Mn-loaded $E c$, the conformation of the F162 side 
chain is not oxidation-state dependent, but rather metal-iontype dependent, since Fe-loaded Ec NrdF (PDB ID: 3N38, Ref. [12]) resembles the (photo-)reduced structures of $B a$ NrdF. Apart from the metal site proximal phenylalanine pair, a glutamate residue equivalent to E161 in $B a$ and located on $\alpha \mathrm{E}$ was proposed to regulate access to the metal site [12, 51]. Therefore, it is possible that there are other oxidationstate-sensing residues involved in locking the NrdF-NrdI superoxide passage in $\mathrm{NrdF}$ proteins. The structural data thus suggest that the passage for the hydrophilic oxidant species from the FMN cofactor in the NrdI to the metal site in the $\mathrm{NrdF}$ is closed once the metal site is oxidized and the $\mathrm{Y}$. is generated. This could prevent premature loss of the radical to solvent and also stop the injection of a second superoxide species, which would likely rapidly quench the tyrosyl radical.

\section{Conclusion}

In the present study, we report several crystal structures of B. anthracis $\mathrm{NrdF}$ - the radical-generating subunit of class Ib RNR. These high-resolution structures allow a detailed analysis of the metallo-cofactor environment and the radical site in the presence of $\mathrm{Mn} / \mathrm{Mn}$ or $\mathrm{Fe} / \mathrm{Fe}$ sites, as well as in the metal-free form. In contrast to Mn-containing $\mathrm{NrdF}$ (most relevant in vivo, Ref. [35-38]), the di-ferrous metallocofactor spontaneously reduces oxygen and forms a di-ferric metallo-cofactor and the Y. in vitro, and possibly in vivo, depending on metal-ion availability. As for the other class $\mathrm{Ib} \mathrm{NrdF}$ proteins characterized to date, $B a \mathrm{NrdF}$ is extremely sensitive to X-ray photo-reduction. Nevertheless, we were able to determine the structure of oxygen-activated di-Fe $\mathrm{NrdF}$ by exposing a crystal to very low intensity X-rays.

Upon metal-ion oxidation and radical generation, $\mathrm{NrdF}$ must effectively initiate radical transfer and protect the radical from premature decay or loss to solvent. The crystal structures reported here exhibit interesting features, likely to be functionally relevant. First, our structures reveal that in $B a \mathrm{NrdF}$, the redox-active tyrosine side chain (Y100) displays conformational flexibility, irrespective of the type of metal-ion bound. These dynamics may be important in radical generation and transfer initiation to the catalytic subunit of RNR, R1. Second, the oxidized di-Fe structure $\left(\mathrm{Fe}_{2}\right.$-semiox $\mathrm{Ba} \mathrm{NrdF}$ ) reveals significant orchestrated conformational changes in the primary and secondary coordination spheres of the metal ions, compared to reduced and photo-reduced $B a$ NrdF. Particularly, a conserved $\pi-/ 3_{10^{-}}$ helical segment of $\alpha \mathrm{E}$, located proximally to the metal site undergoes significant rearrangements, following the oxygen activation. We hypothesize that these structural rearrangements play a central role in sealing the solvent channel, linking the FMN cofactor of NrdI and the metal site in NrdF, and serving as a superoxide passage necessary for di-Mn metallo-cofactor activation in vivo [11-13]. Comparable mechanisms of cofactor shielding have been shown for, e.g., nitrogenase and [FeFe]-hydrogenase, and proposed to be important for correct cofactor assembly [52]. In addition, this $\pi-/ 3_{10}$-helical segment of $\alpha E$ may play a role in insulating the hydrophobic pocket around the $\mathrm{Y}$ - by stacking the strictly conserved Phe169 side chain against the redox-active tyrosine side chain Y100. Together, these findings further emphasize the relevance of structural dynamics in R2 proteins and expand our understanding of radical generation and shielding in RNRs and may be useful for structure-based drug design against anthrax.

Acknowledgements Open access funding was provided by Stockholm University. We thank Margareta Sahlin and Britt-Marie Sjöberg for providing the protein used for initial structure solution, which was not presented here. In addition, we would like to acknowledge staff at the I911-3 beamline of the MAX II synchrotron (Lund, Sweden), for help with data collection. We are grateful to Ramona Kositzki and Michael Haumann for metal content analysis by TXRF. Furthermore, we would like to thank members of Högbom and Stenmark lab, as well as the staff at BL14.1/BESSY (Helmholtz Center Berlin, Germany), X06SA and X06DA/SLS (Villigen, Switzerland) for their technical support and assistance with X-ray data collection. Financial support was provided by the Knut and Alice Wallenberg Foundation (2017.0275), the European Research Council (HIGH-GEAR, 724394), the Swedish Research Council (2017-04018), and the European Community's Seventh Framework Programme (FP7/2007-2013) under grant agreement n. ${ }^{\circ} 283570$ (for BioStruct-X).

Author contributions WL and GB performed protein production and purification. KG and JJG performed metal loading experiments. WL and $\mathrm{KG}$ performed protein crystallization and data collection. WL, $\mathrm{KG}$, JJG, and MDB analyzed X-ray crystallographic data. DL and MH conceived and supervised the study. KG wrote the paper with contributions from all authors. All authors reviewed the results and approved the final version of the manuscript.

\section{Compliance with ethical standards}

Conflict of interest The authors declare no conflict of interest.

Atomic coordinates and structure factors The atomic coordinates and structure factors have been deposited in the Protein Data Bank (http:// wwpdb.org/) with accession codes 6QO5 (metal-free (apo) form of $B a$ $\mathrm{NrdF}$ ), 6QO7 ( $\mathrm{Fe}^{\mathrm{II}}$-loaded $B a \mathrm{NrdF}$ in aerobic conditions, not activated by oxygen), 6QO8 ( $\mathrm{Fe}^{\mathrm{II}}$-loaded $\mathrm{Ba} \mathrm{NrdF}$ in anoxic conditions, not activated by oxygen), $6 \mathrm{QO} 9$ ( $\mathrm{Mn}^{\mathrm{II}}$-loaded $B a \mathrm{NrdF}$ in aerobic conditions, not activated by oxygen), and 6QOB ( $\mathrm{Fe}^{\mathrm{II}}$-loaded $\mathrm{Ba} \mathrm{NrdF}$ in aerobic conditions, partially oxidized state).

Open Access This article is distributed under the terms of the Creative Commons Attribution 4.0 International License (http://creativeco mmons.org/licenses/by/4.0/), which permits unrestricted use, distribution, and reproduction in any medium, provided you give appropriate credit to the original author(s) and the source, provide a link to the Creative Commons license, and indicate if changes were made. 


\section{References}

1. Nordlund P, Reichard P (2006) Ribonucleotide reductases. Annu Rev Biochem 75:681-706. https://doi.org/10.1146/annurev.bioch em.75.103004.142443

2. Hofer A, Crona M, Logan DT, Sjöberg B-M (2012) DNA building blocks: keeping control of manufacture. Crit Rev Biochem Mol Biol 47:50-63. https://doi.org/10.3109/10409238.2011.630372

3. Torrents E (2014) Ribonucleotide reductases: essential enzymes for bacterial life. Front Cell Infect Microbiol 4:52. https://doi. org/10.3389/fcimb.2014.00052

4. Srinivas V, Lebrette H, Lundin D et al (2018) Metal-free ribonucleotide reduction powered by a DOPA radical in Mycoplasma pathogens. Nature 563:416-420. https://doi.org/10.1038/s4158 6-018-0653-6

5. Blaesi EJ, Palowitch GM, Hu K et al (2018) Metal-free class Ie ribonucleotide reductase from pathogens initiates catalysis with a tyrosine-derived dihydroxyphenylalanine radical. Proc Natl Acad Sci USA 115:10022-10027. https://doi.org/10.1073/pnas.18119 93115

6. Cotruvo JA, Stubbe J (2011) Class I ribonucleotide reductases: metallocofactor assembly and repair in vitro and in vivo. Annu Rev Biochem 80:733-767. https://doi.org/10.1146/annurev-bioch em-061408-095817

7. Rozman Grinberg I, Lundin D, Hasan M et al (2018) Novel ATPcone-driven allosteric regulation of ribonucleotide reductase via the radical-generating subunit. Elife $7:$ e31529. https://doi. org/10.7554/eLife.31529

8. Rose HR, Ghosh MK, Maggiolo AO et al (2018) Structural basis for superoxide activation of Flavobacterium johnsoniae class I ribonucleotide reductase and for radical initiation by its dimanganese cofactor. Biochemistry 57:2679-2693. https://doi. org/10.1021/acs.biochem. 8 b00247

9. Lundin D, Torrents E, Poole AM, Sjöberg B-M (2009) RNRdb, a curated database of the universal enzyme family ribonucleotide reductase, reveals a high level of misannotation in sequences deposited to Genbank. BMC Genom 10:589. https://doi. org/10.1186/1471-2164-10-589

10. Cotruvo JA, Stich TA, Britt RD, Stubbe J (2013) Mechanism of assembly of the dimanganese-tyrosyl radical cofactor of class Ib ribonucleotide reductase: enzymatic generation of superoxide is required for tyrosine oxidation via a $\mathrm{Mn}(\mathrm{III}) \mathrm{Mn}(\mathrm{IV})$ intermediate. J Am Chem Soc 135:4027-4039. https://doi.org/10.1021/ja312 $457 \mathrm{t}$

11. Cotruvo JA, Stubbe J (2010) An active dimanganese(III)-tyrosyl radical cofactor in escherichia coli class $\mathrm{Ib}$ ribonucleotide reductase. Biochemistry 49:1297-1309. https://doi.org/10.1021/bi902 106n

12. Boal AK, Cotruvo JA, Stubbe J, Rosenzweig AC (2010) Structural basis for activation of class $\mathrm{Ib}$ ribonucleotide reductase. Science 329:1526-1530. https://doi.org/10.1126/science.1190187

13. Berggren G, Duraffourg N, Sahlin M, Sjöberg BM (2014) Semiquinone-induced maturation of Bacillus anthracis ribonucleotide reductase by a superoxide intermediate. J Biol Chem 289:31940 31949. https://doi.org/10.1074/jbc.M114.592535

14. Torrents E, Sahlin M, Biglino D et al (2005) Efficient growth inhibition of Bacillus anthracis by knocking out the ribonucleotide reductase tyrosyl radical. Proc Natl Acad Sci 102:17946-17951. https://doi.org/10.1073/pnas.0506410102

15. Torrents E, Sahlin M, Biglino D et al (2005) Efficient growth inhibition of Bacillus anthracis by knocking out the ribonucleotide reductase tyrosyl radical. Proc Natl Acad Sci USA 102:1794617951. https://doi.org/10.1073/pnas.0506410102

16. Klockenkämper R (1997) Total-reflection X-ray fluorescence analysis. Wiley, New York
17. Griese JJ, Kositzki R, Schrapers P et al (2015) Structural basis for oxygen activation at a heterodinuclear manganese/iron cofactor. J Biol Chem 290:25254-25272. https://doi.org/10.1074/jbc. M115.675223

18. Matthews BW (1968) Solvent content of protein crystals. J Mol Biol 33:491-497. https://doi.org/10.1016/0022-2836(68)90205-2

19. Kantardjieff KA, Rupp B (2003) Matthews coefficient probabilities: improved estimates for unit cell contents of proteins, DNA, and protein-nucleic acid complex crystals. Protein Sci 12:18651871. https://doi.org/10.1110/ps.0350503

20. Kabsch W (2010) XDS. Acta Crystallogr Sect D Biol Crystallogr 66:125-132. https://doi.org/10.1107/S0907444909047337

21. Potterton E, Briggs P, Turkenburg M et al (2003) A graphical user interface to the CCP4 program suite. Acta Crystallogr Sect D: Biol Crystallogr 59:1131-1137. https://doi.org/10.1107/ S0907444903008126

22. Winn MD, Ballard CC, Cowtan KD et al (2011) Overview of the CCP4 suite and current developments. Acta Crystallogr D Biol Crystallogr 67:235-242. https://doi.org/10.1107/S090744491 0045749

23. Keegan RM, Winn MD (2008) MrBUMP: an automated pipeline for molecular replacement. Acta Crystallogr D Biol Crystallogr 64:119-124. https://doi.org/10.1107/S0907444907037195

24. Vagin A, Teplyakov A (1997) MOLREP: an automated program for molecular replacement. J Appl Crystallogr 30:1022-1025. https://doi.org/10.1107/S0021889897006766

25. Högbom M, Huque Y, Sjöberg BM, Nordlund P (2002) Crystal structure of the di-iron/radical protein of ribonucleotide reductase from Corynebacterium ammoniagenes. Biochemistry 41:1381-1389. https://doi.org/10.1021/bi0114291

26. Vagin A, Teplyakov A (1997) MOLREP: an automated program for molecular replacement. J Appl Crystallogr 30:1022-1025. https://doi.org/10.1107/S0021889897006766

27. Murshudov GN, Vagin AA, Dodson EJ (1997) Refinement of macromolecular structures by the maximum-likelihood method. Acta Crystallogr Sect D Biol Crystallogr 53:240-255. https:// doi.org/10.1107/S0907444996012255

28. Emsley P, Lohkamp B, Scott WG, Cowtan K (2010) Features and development of coot. Acta Crystallogr D Biol Crystallogr 66:486-501. https://doi.org/10.1107/S0907444910007493

29. McCoy AJ, Grosse-Kunstleve RW, Adams PD et al (2007) Phaser crystallographic software. J Appl Crystallogr 40:658674. https://doi.org/10.1107/S0021889807021206

30. Adams PD, Afonine PV, Bunkóczi G et al (2010) PHENIX: a comprehensive python-based system for macromolecular structure solution. Acta Crystallogr Sect D Biol Crystallogr 66:213-221. https://doi.org/10.1107/S0907444909052925

31. Afonine PV, Grosse-Kunstleve RW, Echols N et al (2012) Towards automated crystallographic structure refinement with phenix.refine. Acta Crystallogr D Biol Crystallogr 68:352-367. https://doi.org/10.1107/S0907444912001308

32. Chen VB, Arendall WB, Headd JJ et al (2010) MolProbity: all-atom structure validation for macromolecular crystallography. Acta Crystallogr D Biol Crystallogr 66:12-21. https://doi. org/10.1107/S0907444909042073

33. The PyMOL Molecular Graphics System, Version 2.0.0 Schrödinger, LLC. https://www.pymol.org/citing

34. Laskowski RA, Jabłońska J, Pravda L et al (2018) PDBsum: structural summaries of PDB entries. Protein Sci 27:129-134. https://doi.org/10.1002/pro.3289

35. Cox N, Ogata H, Stolle P et al (2010) A tyrosyl-dimanganese coupled spin system is the native metalloradical cofactor of the $\mathrm{R} 2 \mathrm{~F}$ subunit of the ribonucleotide reductase of Corynebacterium ammoniagenes. J Am Chem Soc 132:11197-11213. https ://doi.org/10.1021/ja1036995 
36. Cotruvo JA, Stubbe J (2011) Escherichia coli class Ib ribonucleotide reductase contains a dimanganese(III)-tyrosyl radical cofactor in vivo. Biochemistry 50:1672-1681. https://doi. org/10.1021/bi101881d

37. Martin JE, Imlay JA (2011) The alternative aerobic ribonucleotide reductase of Escherichia coli, NrdEF, is a manganesedependent enzyme that enables cell replication during periods of iron starvation. Mol Microbiol 80:319-334. https://doi.org/ 10.1111/j.1365-2958.2011.07593.x

38. Zhang Y, Stubbe J (2011) Bacillus subtilis class Ib ribonucleotide reductase is a dimanganese(III)-tyrosyl radical enzyme. Biochemistry 50:5615-5623. https://doi.org/10.1021/bi200348q

39. Tomter AB, Zoppellaro G, Andersen NH et al (2013) Ribonucleotide reductase class I with different radical generating clusters. Coord Chem Rev 257:3-26. https://doi.org/10.1016/j. ccr.2012.05.021

40. Nordlund P, Sjöberg B-M, Eklund H (1990) Three-dimensional structure of the free radical protein of ribonucleotide reductase. Nature 345:593-598. https://doi.org/10.1038/345593a0

41. Sigfridsson KGV, Chernev P, Leidel N et al (2013) Rapid X-ray photoreduction of dimetal-oxygen cofactors in ribonucleotide reductase. J Biol Chem 288:9648-9661. https://doi.org/10.1074/ jbc.M112.438796

42. Griese JJ, Högbom M, Garman EF et al (2012) X-ray reduction correlates with soaking accessibility as judged from four noncrystallographically related diiron sites. Metallomics 4:894. https ://doi.org/10.1039/c2mt20080e

43. Uppsten M, Davis J, Rubin H, Uhlin U (2004) Crystal structure of the biologically active form of class Ib ribonucleotide reductase small subunit from Mycobacterium tuberculosis. FEBS Lett 569:117-122. https://doi.org/10.1016/j.febslet.2004.05.059

44. Högbom M, Galander M, Andersson M et al (2003) Displacement of the tyrosyl radical cofactor in ribonucleotide reductase obtained by single-crystal high-field EPR and 1.4-A X-ray data. Proc Natl Acad Sci USA 100:3209-3214. https://doi.org/10.1073/ pnas.0536684100

45. Galander M, Uppsten M, Uhlin U, Lendzian F (2006) Orientation of the tyrosyl radical in Salmonella typhimurium class $\mathrm{Ib}$ ribonucleotide reductase determined by high field EPR of R2F single crystals. J Biol Chem 281:31743-31752. https://doi. org/10.1074/jbc.M605089200

46. Boal AK, Cotruvo JA, Stubbe J, Rosenzweig AC (2012) The dimanganese(II) site of Bacillus subtilis class Ib ribonucleotide reductase. Biochemistry 51:3861-3871. https://doi.org/10.1021/ bi201925t

47. Weaver TM (2000) The pi-helix translates structure into function. Protein Sci 9:201-206. https://doi.org/10.1110/ps.9.1.201

48. Lundin D, Poole AM, Sjöberg B-M, Högbom M (2012) Use of structural phylogenetic networks for classification of the ferritinlike superfamily. J Biol Chem 287:20565-20575. https://doi. org/10.1074/jbc.M112.367458

49. Cooley RB, Arp DJ, Karplus PA (2010) Evolutionary origin of a secondary structure: $\pi$-helices as cryptic but widespread insertional variations of $\alpha$-helices that enhance protein functionality. $\mathrm{J}$ Mol Biol 404:232-246. https://doi.org/10.1016/j.jmb.2010.09.034

50. Eriksson M, Jordan A, Eklund H (1998) Structure of Salmonella typhimurium nrdF ribonucleotide reductase in its oxidized and reduced forms. Biochemistry 37:13359-13369. https://doi. org/10.1021/bi981380s

51. Hammerstad M, Hersleth H-P, Tomter AB et al (2014) Crystal structure of Bacillus cereus class Ib ribonucleotide reductase diiron NrdF in complex with NrdI. ACS Chem Biol 9:526-537. https://doi.org/10.1021/cb400757h

52. Mulder DW, Boyd ES, Sarma R et al (2010) Stepwise [FeFe]hydrogenase $\mathrm{H}$-cluster assembly revealed in the structure of HydA $\Delta$ EFG. Nature 465:248-251. https://doi.org/10.1038/natur e08993

Publisher's Note Springer Nature remains neutral with regard to jurisdictional claims in published maps and institutional affiliations. 